\title{
Characterization of Circular-Arc Overlap Graphs with Domination Number Two
}

\author{
A. Sudhakaraiah \\ Assistant Professor \\ Dept. of Mathematics \\ S. V. University \\ Tirupathi, A.P, India-513502.
}

\author{
V. Raghava Lakshmi \\ Sr. Asst. Professor \\ Dept. of Mathematics \\ Vijaya Institute of Technology for Women \\ Vijayawada, A.P, India-521108
}

\begin{abstract}
A graph is a circular arc graph if it is the intersection graph of a finite set of arcs on a circle. A circular-arc overlap graph is a special case of circular arc graph; it is an overlap graph defined for a set of arcs on a circle. That is, there is one arc for each vertex of $G$ and two vertices in $G$ are adjacent in $G$ if and only if the corresponding arcs intersect and one is not contained in the other.

In this paper, we emphasize on characterizing circular-arc overlap graphs (CAOG) as partite graphs $\mathrm{k}_{2,2}, \mathrm{k}_{3,3}, \mathrm{k}_{\mathrm{n}, \mathrm{n}}$ and $\mathrm{k}_{2,2,2 \ldots, 2}$. Furthermore, we do characterize circular-arc overlap graphs having any pair of vertices of the graph as a minimal dominating set in terms of the neighborhood of the arcs of the graph. Apart from that, we present an algorithm to check whether the given CAOG has every pair of vertices as minimal dominating set or not.
\end{abstract}

Keywords: Circular-arc overlap graphs, partite graphs, dominating set, minimal dominating set, domination number.

\section{INTRODUCTION}

Recently Kashiwa Bara and Masuda introduced a new class of overlap graphs defined for a set of arcs on a circle, which are called circular-arc overlap graphs and obtained polynomial time algorithms to find an independent set and a maximum clique. The notion and concept of a dominating set is due to Ore [1], Berge [2], Cockayne and Hedetniemi [3]. Also, Waliker et al. [4] have contributed to the theory of domination in graphs, besides many others. Having a representation of a graph with arcs is helpful in solving many combinatorial problems on the graph.

Let $\mathrm{A}=$ $\left\{A_{1} \cdot A_{2}, \ldots, A_{n}\right\}$ be a circular arc family, where each $A_{i}$ is an arc on the circle. Two arcs $A_{i}$ and $A_{j}$ are said to overlap each other if they intersect each other but neither of them contains the other. A graph $\mathrm{G}$ is called a circular-arc overlap graph (CAOG) if there is a one-to-one correspondence between vertex set $\mathrm{V}$ and circular-arc family A. Two vertices in $\mathrm{V}$ are adjacent to each other if and only if the corresponding arcs in A overlap each other. Neighborhood of an $\operatorname{arc} \mathrm{A}_{\mathrm{i}}$ is defined as the set of all arcs belonging to $A$ that overlap the $\operatorname{arc} \mathrm{A}_{\mathrm{i}}$. A set $\mathrm{S}$ of vertices in a graph $\mathrm{G}(\mathrm{V}, \mathrm{E})$ is called a dominating set, if every vertex of $\mathrm{V}$ is either an element of $\mathrm{S}$ or adjacent to an element of $\mathrm{S}$. A dominating set is said to be minimal if any of its proper subset is not a dominating set. The domination number of $\mathrm{G}$ is the cardinality of the minimum dominating set.

\section{THEOREMS}

Theorem 1: Let $A=\{1,2,3,4\}$ be a circular arc family corresponding to a circular arc overlap graph $\mathrm{G}$ of order 4 . Then the circular arc family satisfies the conditions

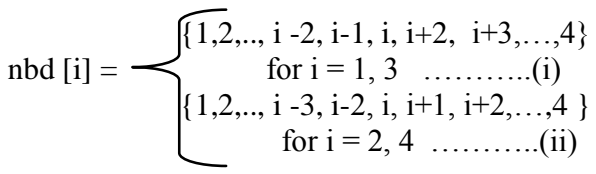

if and only if $\mathrm{G}$ is a $\mathrm{k}_{2,2}$ graph.

Proof: Let $\mathrm{A}=\{1,2,3,4\}$ be a circular arc family corresponding to a circular-arc overlap graph $\mathrm{G}$ of order 4 . As $\mathrm{G}$ is a circular-arc overlap graph, there exists one-to-one correspondence between the vertex set $V=\left\{v_{1}, v_{2}, v_{3}, v_{4}\right\}$ of $G$ and the circular arc Family $A$. Let $v_{i}$ be the vertex corresponding to the arc $i$ for $i=1,2, \ldots, 4$. First, let us suppose that the family A satisfies the conditions (i) and (ii) stated in the theorem. Then, we get

$\operatorname{nbd}[1]=\{1,3,4\}$

$\operatorname{nbd}[2]=\{2,3,4\}$

$\operatorname{nbd}[3]=\{1,2,3\}$

$\operatorname{nbd}[4]=\{1,2,4\}$

The edges of the graph are $\left\{\mathrm{v}_{1}, \mathrm{v}_{3}\right\},\left\{\mathrm{v}_{1}, \mathrm{v}_{4}\right\}, \quad\left\{\mathrm{v}_{2}, \mathrm{v}_{3}\right\}$ and $\left\{\mathrm{v}_{2}, \mathrm{v}_{4}\right\}$. Therefore the sets of vertices $\left\{\mathrm{v}_{1}, \mathrm{v}_{2}\right\}$ and $\left\{\mathrm{v}_{3}, \mathrm{v}_{4}\right\}$ are independent sets and moreover every vertex in the set $\left\{\mathrm{v}_{1}, \mathrm{v}_{2}\right\}$ is adjacent to every vertex in the set $\left\{\mathrm{v}_{3}, \mathrm{v}_{4}\right\}$. Then $\mathrm{G}$ is a bipartite graph with partites $\left\{\mathrm{v}_{1}, \mathrm{v}_{2}\right\}$ and $\left\{\mathrm{v}_{3}, \mathrm{v}_{4}\right\}$. Hence $\mathrm{G}=$ $\mathrm{k}_{2,2}$.

Conversely, let $\mathrm{G}=\mathrm{k}_{2,2}$ graph with two partites $\mathrm{U}=\left\{\mathrm{v}_{1}, \mathrm{v}_{2}\right\}$ and $V=\left\{v_{3}, v_{4}\right\}$. Then $U$ and $V$ are independent sets and there exists an edge between every vertex in $U$ to each vertex in $\mathrm{V}$. Then the edges of the graph are $\left\{\mathrm{v}_{1}, \mathrm{v}_{3}\right\},\left\{\mathrm{v}_{1}, \mathrm{v}_{4}\right\},\left\{\mathrm{v}_{2}, \mathrm{v}_{3}\right\}$ and $\left\{\mathrm{v}_{2}, \mathrm{v}_{4}\right\}$. This happens only when the circular arc family satisfies the conditions (i) and (ii) stated in the theorem.

Theorem 2: Let $\mathrm{A}=\{1,2,3,4,5,6\}$ be a circular arc family corresponding to a circular arc overlap graph $\mathrm{G}$ of order 6 . Then the circular arc family satisfies the conditions

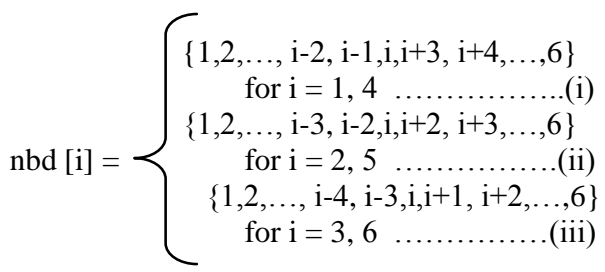

if and only if $\mathrm{G}$ is a $\mathrm{k}_{3,3}$ graph. 
Proof: Let $\mathrm{A}=\{1,2,3,4,5,6\}$ be a circular arc family corresponding to a circular-arc overlap graph $\mathrm{G}$ of order 6 . Let $v_{i}$ be the vertex corresponding to the arc $i$ for $i=1,2, \ldots, 6$. First, let us suppose that the circular arc family A satisfies the conditions stated in the theorem. Then, we have nbd [1] $=\{1,4$, $5,6\}$

$\operatorname{nbd}[2]=\{2,4,5,6\}$

$\operatorname{nbd}[3]=\{3,4,5,6\}$

nbd $[4]=\{1,2,3,4\}$

$\operatorname{nbd}[5]=\{1,2,3,5\}$

nbd $[6]=\{1,2,3,6\}$

The edges of the graph are $\left\{\mathrm{v}_{1}, \mathrm{v}_{4}\right\},\left\{\mathrm{v}_{1}, \mathrm{v}_{5}\right\}, \quad\left\{\mathrm{v}_{1}, \mathrm{v}_{6}\right\},\left\{\mathrm{v}_{2}\right.$, $\left.\mathrm{v}_{4}\right\},\left\{\mathrm{v}_{2}, \mathrm{v}_{5}\right\},\left\{\mathrm{v}_{2}, \mathrm{v}_{6}\right\},\left\{\mathrm{v}_{3}, \mathrm{v}_{4}\right\}, \quad\left\{\mathrm{v}_{3}, \mathrm{v}_{5}\right\}$ and $\left\{\mathrm{v}_{3}, \mathrm{v}_{6}\right\}$. Therefore the sets of vertices $\left\{\mathrm{v}_{1}, \mathrm{v}_{2}, \mathrm{v}_{3}\right\}$ and $\left\{\mathrm{v}_{4}, \mathrm{v}_{5}, \mathrm{v}_{6}\right\}$ are independent sets and moreover every vertex in the set $\left\{\mathrm{v}_{1}, \mathrm{v}_{2}\right.$, $\left.v_{3}\right\}$ is adjacent to every vertex in the set $\left\{v_{4}, v_{5}, v_{6}\right\}$. Then $G$ is a bi-partite graph with partites $\left\{\mathrm{v}_{1}, \mathrm{v}_{2}, \mathrm{v}_{3}\right\}$ and $\left\{\mathrm{v}_{4}, \mathrm{v}_{5}, \mathrm{v}_{6}\right\}$. Hence $\mathrm{G}=\mathrm{k}_{3,3}$.

Conversely, let $\mathrm{G}=\mathrm{k}_{3,3}$ graph. Then $\mathrm{G}$ has two partites, each partite consisting of three vertices. Let $U=\left\{\mathrm{v}_{1}, \mathrm{v}_{2}, \mathrm{v}_{3}\right\}$ and $\mathrm{V}=$ $\left\{v_{4}, v_{5}, v_{6}\right\}$ be the two partites of the graph G. Then $U$ and $V$ are independent sets and every vertex in $U$ is adjacent to each vertex in $\mathrm{V}$. Hence the edges of the graph are $\left\{\mathrm{v}_{1}, \mathrm{v}_{4}\right\},\left\{\mathrm{v}_{1}, \mathrm{v}_{5}\right\}$, $\left\{\mathrm{v}_{1}, \mathrm{v}_{6}\right\} ;\left\{\mathrm{v}_{2}, \mathrm{v}_{4}\right\},\left\{\mathrm{v}_{2}, \mathrm{v}_{5}\right\},\left\{\mathrm{v}_{2}, \mathrm{v}_{6}\right\},\left\{\mathrm{v}_{3}, \mathrm{v}_{4}\right\},\left\{\mathrm{v}_{3}, \mathrm{v}_{5}\right\}$ and $\left\{\mathrm{v}_{3}\right.$, $\left.v_{6}\right\}$. This happens only when the circular arc family satisfies the conditions (i), (ii) and (iii) mentioned in the theorem.

Theorem 3: Let $\mathrm{A}=\{1,2,3,4,5,6, \ldots \ldots, 2 \mathrm{n}\}$ be a circular arc family corresponding to a circular arc overlap graph $\mathrm{G}$ of order $2 \mathrm{n}$. Then the circular arc family satisfies the conditions

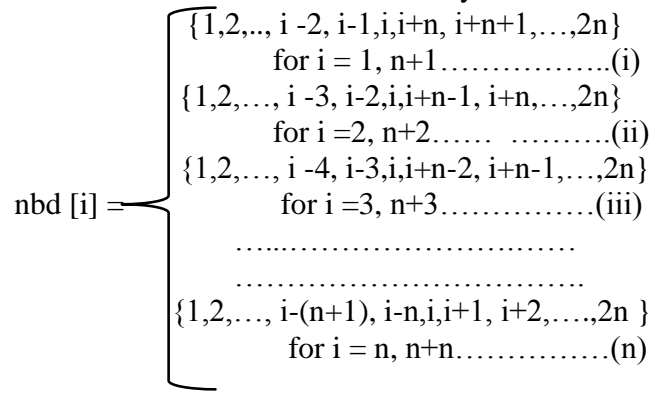

if and only if $\mathrm{G}$ is a $\mathrm{k}_{\mathrm{n}, \mathrm{n}}$ graph.

Proof: Let $\mathrm{A}=\{1,2,3, \ldots \ldots \ldots, 2 \mathrm{n}\}$ be a circular arc family corresponding to a circular-arc overlap graph $\mathrm{G}$ of order $2 \mathrm{n}$. Let $v_{i}$ be the vertex corresponding to the arc $i$, for $i=1,2, \ldots, 2 n$.

First, let us suppose that the family A satisfies the conditions stated in the theorem.

We get

$$
\begin{aligned}
& \operatorname{nbd}[1]=\{1, \mathrm{n}+1, \mathrm{n}+2, \ldots \ldots, 2 \mathrm{n}\} \\
& \operatorname{nbd}[2]=\{2, n+1, n+2, \ldots \ldots, 2 n\} \\
& \operatorname{nbd}[n]=\{n, n+1, n+2, \ldots \ldots, 2 n\} \\
& \operatorname{nbd}[\mathrm{n}+1]=\{1,2, \ldots \ldots \ldots \ldots, n, n+1\} \\
& \operatorname{nbd}[\mathrm{n}+2]=\{1,2, \ldots \ldots \ldots \ldots, \mathrm{n}, \mathrm{n}+2\}
\end{aligned}
$$

$\operatorname{nbd}[2 n]=\{1,2, \ldots \ldots \ldots \ldots, n, n+n\}$

Therefore the sets of vertices $\{1,2, \ldots \ldots, n\}$ and $\{\mathrm{n}+1, \mathrm{n}+2, \ldots \ldots, \mathrm{n}+\mathrm{n}\}$ are independent sets and moreover, every vertex in the set $\{1,2, \ldots \ldots, n\}$ is adjacent to every vertex in the set $\{n+1, n+2, \ldots \ldots, 2 n\}$. Then, $G$ is a bi-partite graph with partites $\{1,2, \ldots \ldots, n\}$ and $\{n+1, n+2, \ldots \ldots, 2 n\}$. Hence, $G=k_{n, n}$.
Conversely, let $\mathrm{G}=\mathrm{k}_{\mathrm{n}, \mathrm{n}}$ graph. Then $\mathrm{G}$ has two partites, each partite consists of $\mathrm{n}$ vertices. Let $\mathrm{U}=\left\{\mathrm{v}_{1}, \mathrm{v}_{2}, \ldots \ldots \ldots \ldots, \mathrm{v}_{\mathrm{n}}\right\}$ and

$\mathrm{V}=\left\{\mathrm{v}_{\mathrm{n}+1}, \mathrm{v}_{\mathrm{n}+2}, \ldots . ., \mathrm{v}_{2 \mathrm{n}}\right\}$ be the two partites of the graph $\mathrm{G}$. Then $\mathrm{U}$ and $\mathrm{V}$ are independent sets and there exists an edge between every vertex in $\mathrm{U}$ to every vertex in $\mathrm{V}$. Hence the edges of the graph are
$\left\{\mathrm{v}_{1}, \mathrm{v}_{\mathrm{n}+1}\right\},\left\{\mathrm{v}_{1}, \mathrm{v}_{\mathrm{n}+2}\right\}, \ldots .,\left\{\mathrm{v}_{1}, \mathrm{v}_{2 \mathrm{n}}\right\}$
$\left\{\mathrm{v}_{2}, \mathrm{v}_{\mathrm{n}+1}\right\},\left\{\mathrm{v}_{2}, \mathrm{v}_{\mathrm{n}+2}\right\}, \ldots \ldots \ldots,\left\{\mathrm{v}_{2}, \mathrm{v}_{2 \mathrm{n}}\right\}$;
................
$\left\{\mathrm{v}_{\mathrm{n}}, \mathrm{v}_{\mathrm{n}+1}\right\}\left\{\mathrm{v}_{\mathrm{n}}, \mathrm{v}_{\mathrm{n}+2}\right\}, \ldots \ldots \ldots,\left\{\mathrm{v}_{\mathrm{n}}, \mathrm{v}_{2 \mathrm{n}}\right\} ;$
$\left\{\mathrm{v}_{\mathrm{n}+1}, \mathrm{v}_{1}\right\},\left\{\mathrm{v}_{\mathrm{n}+1}, \mathrm{v}_{2}\right\}, \ldots \ldots \ldots,\left\{\mathrm{v}_{\mathrm{n}+1}, \mathrm{v}_{\mathrm{n}}\right\}$;
$\left\{\mathrm{v}_{\mathrm{n}+2}, \mathrm{v}_{1}\right\},\left\{\mathrm{v}_{\mathrm{n}+2}, \mathrm{v}_{2}\right\}, \ldots \ldots \ldots,\left\{\mathrm{v}_{\mathrm{n}+2}, \mathrm{v}_{\mathrm{n}}\right\}$;

$\left\{\mathrm{v}_{2 \mathrm{n}}, \mathrm{v}_{1}\right\}\left\{\mathrm{v}_{2 \mathrm{n}}, \mathrm{v}_{2}\right\}, \ldots \ldots \ldots,\left\{\mathrm{v}_{2 \mathrm{n}}, \mathrm{v}_{\mathrm{n}}\right\}$

This happens only when the circular arc family satisfies the conditions (i),(ii),.....,(n) mentioned in the theorem.

\section{Theorem 4:}

Let $\mathrm{A}=\{1,2,3, \ldots, 2 \mathrm{n}\}$ be a circular arc family corresponding to a circular arc overlap graph $\mathrm{G}$ of order $2 \mathrm{n}$. Then the circular arc family satisfies the conditions

$$
\begin{gathered}
\{1,2, \ldots, \mathrm{i}-2, \mathrm{i}-1, \mathrm{i}, \mathrm{i}+2, \mathrm{i}+3, \ldots, 2 \mathrm{n}\} \\
\text { for } \mathrm{i}=1,3, \ldots \ldots, 2 \mathrm{n}-1 \ldots \ldots .(\mathrm{i}) \\
\text { nbd }[\mathrm{i}]=\quad \begin{array}{c}
1,2, \ldots, \mathrm{i}-3, \mathrm{i}-2, \mathrm{i}, \mathrm{i}+1, \mathrm{i}+2, \ldots ., 2 \mathrm{n}\} \\
\text { for } \mathrm{i}=2,4 \ldots \ldots .2 \mathrm{n} \quad \ldots \ldots \ldots \ldots \text { (ii) }
\end{array}
\end{gathered}
$$

if and only if any pair of vertices of $\mathrm{G}$ forms a minimal dominating set of $\mathrm{G}$.

Proof: Let $\mathrm{A}=\{1,2,3, \ldots \ldots, 2 \mathrm{n}\}$ be a circular arc family corresponding to a circular-arc overlap graph $\mathrm{G}$ of order $2 \mathrm{n}$. Let $v_{i}$ be the vertex corresponding to the $\operatorname{arc} i$, for $i=1,2, \ldots, 2 n$. First, let us suppose that the family A satisfies the conditions (i) and (ii) stated in the theorem. We have

$\operatorname{nbd}[1]=\{1,3,4, \ldots \ldots \ldots \ldots .2 \mathrm{n}\}$
$\operatorname{nbd}[2]=\{2,3,4, \ldots \ldots \ldots \ldots \ldots, 2 \mathrm{n}\}$
$\operatorname{nbd}[3]=\{1,2,3,5,6, \ldots \ldots ., 2 \mathrm{n}\}$
$\operatorname{nbd}[4]=\{1,2,4,5,6, \ldots \ldots, 2 \mathrm{n}\}$

nbd $[2 \mathrm{n}]=\{1,2,3, \ldots, 2 \mathrm{n}-2,2 \mathrm{n}\}$

The edges of the graph are

$\left.\left\{\mathrm{v}_{1}, \mathrm{v}_{3}\right\},\left\{\mathrm{v}_{1}, \mathrm{v}_{4}\right\}, \ldots \ldots \ldots \ldots \ldots \ldots \ldots . . \ldots \ldots \ldots, \mathrm{v}_{1}, \mathrm{v}_{2 \mathrm{n}}\right\}$;

$\left\{\mathrm{v}_{2}, \mathrm{v}_{3}\right\}\left\{\mathrm{v}_{2}, \mathrm{v}_{4}\right\}, \ldots \ldots \ldots \ldots \ldots \ldots,\left\{\mathrm{v}_{2}, \mathrm{v}_{2 \mathrm{n}}\right\} ;$

$\left\{\mathrm{v}_{3}, \mathrm{v}_{1}\right\},\left\{\mathrm{v}_{3}, \mathrm{v}_{2}\right\},\left\{\mathrm{v}_{3}, \mathrm{v}_{5}\right\}, \ldots \ldots \ldots \ldots,\left\{\mathrm{v}_{3}, \mathrm{v}_{2 \mathrm{n}}\right\} ; \quad\left\{\mathrm{v}_{4}, \mathrm{v}_{1}\right\},\left\{\mathrm{v}_{4}\right.$

, $\left.\mathrm{v}_{2}\right\},\left\{\mathrm{v}_{4}, \mathrm{v}_{5}\right\}, \ldots \ldots \ldots,\left\{\mathrm{v}_{4}, \mathrm{v}_{2 \mathrm{n}}\right\}$;

$\left\{\mathrm{v}_{2 \mathrm{n}-1}, \mathrm{v}_{1}\right\},\left\{\mathrm{v}_{2 \mathrm{n}-1}, \mathrm{v}_{2}\right\}, \ldots \ldots \ldots,\left\{\mathrm{v}_{2 \mathrm{n}-1}, \mathrm{v}_{2 \mathrm{n}-2}\right\}$

$\left\{\mathrm{v}_{2 \mathrm{n}}, \mathrm{v}_{1}\right\},\left\{\mathrm{v}_{2 \mathrm{n}}, \mathrm{v}_{2}\right\}, \ldots \ldots \ldots \ldots \ldots,\left\{\mathrm{v}_{2 \mathrm{n}}, \mathrm{v}_{2 \mathrm{n}-2}\right\}$.

The sets of vertices $\left\{\mathrm{v}_{1}, \mathrm{v}_{2}\right\},\left\{\mathrm{v}_{3}, \mathrm{v}_{4}\right\}, \ldots,\left\{\mathrm{v}_{2 \mathrm{n}-1}, \mathrm{v}_{2 \mathrm{n}}\right\}$ are independent sets and moreover every vertex in each set is adjacent to every other vertex in the remaining sets. Hence $G$ is a $\mathrm{n} / 2$-partite graph with partites $\left\{\mathrm{v}_{1}, \mathrm{v}_{2}\right\},\left\{\mathrm{v}_{3}, \mathrm{v}_{4}\right\}, \ldots \ldots \ldots,\left\{\mathrm{v}_{2} \mathrm{n}\right.$ $\left.{ }_{1}, \mathrm{v}_{2 \mathrm{n}}\right\}$. Implies,

$\mathrm{G}=\mathrm{k}_{2,2, \ldots \ldots \ldots . . .2}$. For any complete k-partite graph, any two adjacent vertices form a dominating set. Here the graph $\mathrm{G}$ is not only a complete k- partite graph, it is a $\mathrm{k}_{2,2, \ldots ., 2}$ graph (complete $\mathrm{n} / 2$-partite graph). Hence any two vertices form a dominating set. 
Conversely, let every pair of vertices in $G$ form a minimal dominating set of $\mathrm{G}$. Every pair of adjacent vertices also forms a minimal dominating set of $\mathrm{G}$. Let the chromatic number of $\mathrm{G}$ be p.

Let the vertex set $\mathrm{V}$ of $\mathrm{G}$ be partitioned into ' $\mathrm{p}$ ' independent sets $\mathrm{V}_{1}, \mathrm{~V}_{2}, \mathrm{~V}_{3}, \ldots \ldots . ., \mathrm{V}_{\mathrm{p}}$ where $\mathrm{V}_{1}, \mathrm{~V}_{2}, \mathrm{~V}_{3}, \ldots \ldots \ldots, \mathrm{Vp}$ are the distinct color classes of $G$ [5]. Since chromatic number of $G$ is $\mathrm{p}$, there exists at least one edge between the vertices of any two distinct color classes of $\mathrm{G}$. Let the edge between two color classes $\mathrm{V}_{1}$ and $\mathrm{V}_{2}$ be $\{\mathrm{u}, \mathrm{v}\}$ where $\mathrm{u}$ belongs to $\mathrm{V}_{1}$ and $\mathrm{v}$ belongs to $\mathrm{V}_{2}$. Therefore the set $\{\mathrm{u}, \mathrm{v}\}$ is a minimal dominating set. Since $\mathrm{V}_{1}$ and $\mathrm{V}_{2}$ are independent sets and the set $\{\mathrm{u}, \mathrm{v}\}$ is a minimal dominating set, the vertex $u$ is adjacent to every vertex in $\mathrm{V}_{2}$ and the vertex $\mathrm{v}$ is adjacent to every vertex in $\mathrm{V}_{1}$. In the similar manner, we can prove that every vertex in the set $\mathrm{V}_{\mathrm{i}}$ is adjacent to every vertex in $\mathrm{V}_{\mathrm{j}}$ for $\mathrm{i} \neq \mathrm{j}$. Hence the sets $\mathrm{V}_{1}, \mathrm{~V}_{2}, \mathrm{~V}_{3}, \ldots, \mathrm{V}_{\mathrm{p}}$ are independent sets and every vertex in one color class is adjacent to every vertex in another color class. So, the sets $\mathrm{V}_{1}, \mathrm{~V}_{2}, \mathrm{~V}_{3}, \ldots \ldots \ldots, \mathrm{V}_{\mathrm{P}}$ can be considered as the partites of the graph. Therefore

$$
\mathrm{G}=\mathrm{Kv}_{1}, \mathrm{v}_{2}, \ldots \ldots, \mathrm{v}_{\mathrm{p}} \text {. }
$$

But any two non-adjacent vertices also form a dominating set of G. So, each partite consists of only two vertices. Hence, $\mathrm{G}$ is a complete partite graph with ' $n$ ' partites, each equipped with two vertices. Therefore, $G=k_{2,2}, \ldots \ldots, 2$. This happens only in the case when the circular arc family satisfies the conditions mentioned in the statement of the theorem.

\subsection{Illustration:}

Let the circular arc family $\mathrm{A}=\{1,2, \ldots \ldots, 6\}$ corresponding to the circular-arc overlap graph be as follows.

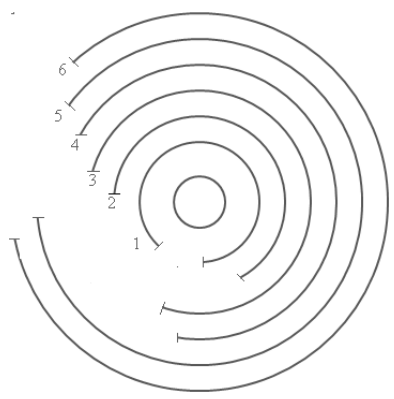

Fig.1 Circular-arc overlap family

In this case,

$$
\begin{aligned}
& \operatorname{nbd}[1]=\{1,3,4,5,6\} \\
& \operatorname{nbd}[2]=\{2,3,4,5,6\} \\
& \operatorname{nbd}[3]=\{1,2,3,5,6\} \\
& \operatorname{nbd}[4]=\{1,2,4,5,6\} \\
& \operatorname{nbd}[5]=\{1,2,3,4,5\} \\
& \operatorname{nbd}[6]=\{1,2,3,4,6\}
\end{aligned}
$$

Clearly, the circular arc family satisfies the conditions mentioned in the theorem for $n=3$. Hence, every pair of vertices in $\mathrm{G}$ forms a minimal dominating set.

\subsubsection{Verification:}

The graph $\mathrm{G}$ in this case is as follows:

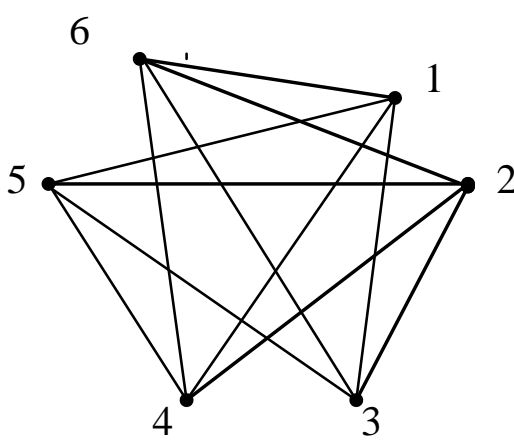

\section{Fig.2. Circular-arc overlap Graph}

Consider the sets $\{1,2\},\{3,4\} \&\{5,6\}$ as partites of the graph. Then the graph $\mathrm{G}$ can also be drawn as follows:

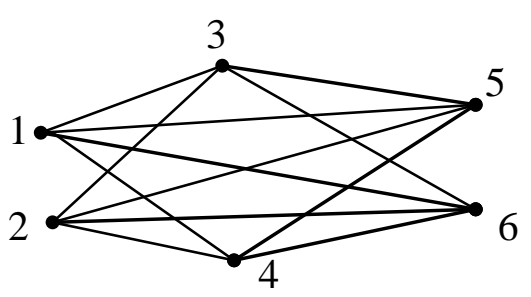

Fig.3 Circular-arc overlap partite graph $\mathbf{K}_{2,2,2}$

From the graph it is clear that, $\mathrm{G}=\mathrm{k}_{2,2,2}$ with partites $\{1,2\}$, $\{3,4\}$ and $\{5,6\}$. Also the sets $\{1,2\},\{1,3\}\{1,4\},\{1,5\},\{1,6\}$, $\{2,3\},\{2,4\}, \quad\{2,5\},\{2,6\}, \quad\{3,4\},\{3,5\},\{3,6\},\{4,5\},\{4,6\}$ and $\{5,6\}$ are all minimal dominating sets of G. Hence every pair of vertices of a graph $\mathrm{G}$ forms a minimal dominating set if the corresponding CAOG satisfies the conditions mentioned in the theorem. Hence the given theorem is verified.

\section{ALGORITHM:}

In this section, we present an algorithm to check whether the given CAOG has every pair of vertices as a minimal dominating set or not.

Input : Circular arc family $\mathrm{A}=\{1,2, \ldots \ldots \ldots, 2 \mathrm{n}\}$

Output : Every pair of vertices is a minimal dominating set of CAOG

1 : Find nbd [i], for $\mathrm{i}=1$ to $2 \mathrm{n}$

2 : If $i=1,3, \ldots \ldots, 2 n-1$, go to step 3

Else

go to step 4

3 : If nbd $[\mathrm{i}]=\{1,2, \ldots, \mathrm{i}-2, \mathrm{i}-1, \mathrm{i}, \mathrm{i}+2$, $\mathrm{i}+3, \ldots \ldots \ldots, 2 \mathrm{n}\}$, then go to step 6

Else

Every pair of vertices is not a minimal Dominating set of $\mathrm{G}$

$4:$ If $n b d[i]=\{1,2, \ldots, i-3, i-2, i, i+1$, $\mathrm{i}+2, \ldots \ldots \ldots, 2 \mathrm{n}\}$, go to step 6

Else

Every pair of vertices is not a minimal Dominating set of $\mathrm{G}$ 


\section{CONCLUSION}

Circular graphs are rich in combinatorial structures and have found applications in several disciplines such as Biology, Ecology, Traffic control, Genetics and Computer Science and particularly useful in cyclic scheduling and computer storage allocation problems. In this paper, we individualized circular-arc overlap graphs as various complete partite graphs. We then extended the results to trace out a specific type of circular- arc overlap graphs having every pair of vertices as a minimal dominating set. Moreover, we presented an algorithm to identify circulararc overlap graphs having every pair of vertices as a minimal dominating set.

\section{REFERENCES}

[1] O. Ore. Theory of Graphs, Ann. Math. Soc. Colloq. Publ. 38. Providence, 1962

[2] C. Berge. Graphs and Hypergraphs, North-Holland, Amsterdam 1973.

[3] E. J. Cockayne and S. T. Hedetniemi. Networks 7(1977), 247-261.

[4] H. B. Walikar, B. D. Acharya and E. Sampathkumar. Recent Developments in the theory oh Dominatio in Graphs, In: MRI Lecture Notes No. 1. Allahabad 1979.

[5] S. R. Jayaram. Indian J. purepl. Math., 28(1) : 43-46, January 1997. 